\title{
Recombinant cell bioassays for the detection of (gluco) corticosteroids and endocrine-disrupting potencies of several environmental PCB contaminants
}

\author{
Toine F. H. Bovee • Richard J. R. Helsdingen • \\ Astrid R. M. Hamers • Bram A. Brouwer • \\ Michel W. F. Nielen
}

Received: 14 April 2011 /Revised: 27 May 2011 / Accepted: 2 June 2011 /Published online: 18 June 2011

(C) The Author(s) 2011. This article is published with open access at Springerlink.com

\begin{abstract}
Sensitive and robust bioassays for glucocorticoids are very useful for the pharmaceutical industry, environmental scientists and veterinary control. Here, a recombinant yeast cell was constructed that expresses the human glucocorticoid receptor alpha and a green fluorescent reporter protein in response to glucocorticoids. Both the receptor construct and the reporter construct were stably integrated into the yeast genome. The correct and specific functioning of this yeast glucocorticoid bioassay was studied by exposures to cortisol and other related compounds and critically compared to a GR-CALUX bioassay based on a human bone cell. Although less sensitive, the new yeast glucocorticoid bioassay showed sensitivity towards all (gluco)corticoids tested, with the following order in relative potencies: budesonide $>>$ corticosterone $>$ dexamethasone $>$ cortisol $=$ betamethasone $>$ prednisolone $>$ aldosterone. Hormone representatives for other hormone nuclear receptors, like $17 \beta$-estradiol for the oestrogen receptor, $5 \alpha$-dihydrotestosterone for the androgen receptor
\end{abstract}

T. F. H. Bovee $(\varangle) \cdot$ R. J. R. Helsdingen · A. R. M. Hamers

M. W. F. Nielen

RIKILT-Institute of Food Safety,

Wageningen University and Research Centre,

Akkermaalsbos 2,

6708 WB Wageningen, the Netherlands

e-mail: toine.bovee@wur.nl

B. A. Brouwer

BioDetection Systems B.V. (BDS),

Kruislaan 406,

1098 SM Amsterdam, the Netherlands

M. W. F. Nielen

Laboratory of Organic Chemistry, Wageningen University,

Dreijenplein 8 ,

$6703 \mathrm{HB}$ Wageningen, the Netherlands and progesterone for the progesterone receptor, showed no clear agonistic responses, whilst some polychlorinated biphenyls were clearly able to interfere with the GR activity.

Keywords Activity screening · Bioassay - Contaminants . Detection · Glucocorticoid receptor

\section{Introduction}

There is an overwhelming amount of evidence that certain chemicals, also present in our environment, food and water, can affect human health by disrupting the endocrine system, possibly leading to adverse effects. Examples include reproductive failure and tumour formation in sensitive target tissues [1, 2]. Most attention has been paid to compounds that are able to alter the activity of the human oestrogen receptor (hER) or androgen receptor (hAR) directly $[3,4]$. Both the ER and AR belong to a large superfamily of receptors, called nuclear receptors. This class of receptors also includes the retinoic acid receptor, vitamin D receptor, progesterone receptor (PR), thyroid receptor, peroxisome proliferator-activated receptor, mineralocorticoid receptor (MR) and the glucocorticoid receptor (GR). There are a lot of bioassays available for the oestrogens and androgens and only a few for the other hormones. Oestrogens and androgens draw a lot of attention because their congruent receptors are involved in many diseases and because oestrogens and androgens are relatively very potent [5]. However, although glucocorticoids are relatively less potent, they are extremely interesting as, in contrast to the hER and hAR that are mainly expressed in the sex organs, the human glucocorticoid receptor (hGR) is expressed in every cell type [6]. 
The hGR is encoded by gene NR3C 1 on chromosome 5 (5q31-32) [7-9] and is involved in the regulation of a wide variety of processes, including development, metabolism, bone density, and growth of cells and also affects the cardiovascular system, the hypothalamic-pituitary-adrenal axis, the immune response and behaviour [10-12]. The hGR is present in two main isoforms, hGR $\alpha$ and hGR $\beta$. Both isoforms are largely identical, but the $\beta$-splice variant misses helix 12 which is an essential part of the ligandbinding domain (LBD). Only hGR $\alpha$ is therefore able to bind ligands effectively and is subsequently capable of binding and activating glucocorticoid-responsive elements (GRE) on the DNA transcriptional level. The physiologic importance of hGR $\beta$ on the other hand is still uncertain $[9$, 13-15]. In humans, the main corticoids are produced in different parts of the adrenal glands. The glucocorticoid cortisol is produced in the fasciculate and the mineralocorticoid aldosterone in the glomerulosa, whilst DHEA sulphate, which is a precursor for androgens and oestrogens, is produced in the reticularis [16]. Altered cortisol production can hamper the general metabolism, immune response and stress resistance [17]. Aldosterone is involved in sodium/ potassium homeostasis, and strong inhibition of aldosterone secretion will result in the salt-wasting characteristics of Addison's disease [18].

Glucocorticoids are potent pharmaceuticals, and although their modes of action are not fully understood, they are successfully used for the therapeutic treatment of patients with a variety of disorders and diseases. The synthetic glucocorticoid dexamethasone for instance is used for the treatment of rheumatoid arthritis and is given to cancer patients to counteract certain side effects of their chemotherapy $[19,20]$. In livestock production, glucocorticoids are administered because of their inhibition of inflammatory, allergic and immunological responses, and as such can be misused to mask bad nursing, housekeeping and feeding of animals. Moreover, glucocorticoids are very tempting for broilers as they also stimulate growth and improve feed conversion [21-24]. Due to the potential health effects, maximum residue limits for these compounds have been established in milk and tissues intended for human consumption, whilst the application of glucocorticoids as growth promoters is banned in the European Union [25-27]. Polychlorinated biphenyls (PCBs) are widespread environmental pollutants, and although their production and commercialisation has been largely prohibited since the 1970s, their chemical stability, persistency and lipophilic character resulted in their tendency to accumulate in the food chain, environment, wildlife and humans. They can be found in human samples such as blood serum, cord blood and breast milk. PCB101 and its $3 \mathrm{MeSO}_{2}$ metabolite are among the most abundant $\mathrm{PCBs}$ present in humans and wildlife [28].
Applicable bioassays for glucocorticoids are useful for the pharmaceutical industry, i.e. to develop compounds with specific agonistic and antagonistic properties; environmental scientists, i.e. to characterise contaminants; and the veterinary control, i.e. to detect the illegal use of corticosteroids. This study describes the development of a yeast glucocorticoid bioassay based on the constitutive expression of hGR $\alpha$ and a green fluorescent reporter protein upon exposure to glucocorticoids. The sensitivity and specificity of this bioassay was determined by testing a range of natural and synthetic (gluco) corticoids and several environmental PCB contaminants known to affect the human endocrine system.

\section{Materials and methods}

\section{Chemicals}

Alosterone, betamethasone, budesonide, corticosterone, cortisol, cortisone, $5 \alpha$-dihydrotestosterone ( $5 \alpha$-DHT), dexamethasone (Dex), $17 \beta$-estradiol (E2), fludrocortisone21-acetate, mifepristone, prednisolone, prednisone, progesterone (P4) and triamcinolone were obtained from Sigma; $17 \beta$-testosterone $(\mathrm{T})$ from Steraloids; and dimethyl sulfoxide (DMSO) from Merck. Org 34116, Org 34517 and Org 34850 were kindly provided by Dr. Willem Schoonen from MSD (Oss, the Netherlands); PCB47, PCB92, PCB100 and PCB101 were provided by Dr. Majorie van Duursen from IRAS (Utrecht, the Netherlands) who obtained these PCBs from Neosync, Inc., USA. Possible impurities in these PCB standards were removed by a cleanup over an active carbon column. Chemicals to prepare the growth media and the preparation of the growth media for both the yeast cells as the U2-OS cell line were as described elsewhere [29, 30].

\section{Plasmids}

The p403-GPD-His yeast vector described by Mumberg et al. [31] was used for the expression of the human glucocorticoid receptor $\alpha$. This plasmid contains the HIS3 marker gene and the strong constitutive yeast glyceraldehyde-3-phosphate dehydrogenase (GPD) promoter. This plasmid was previously used to obtain high expression levels of the $\mathrm{hER} \alpha, \mathrm{hER} \beta$ and $\mathrm{hAR}$ in yeast $[32,33]$. The $\mathrm{pCDNA} 3 / \mathrm{hGR} \alpha$ plasmid containing the full-length cDNA of the hGR $\alpha$ was a gift from Michael Garabedian (NYU).

\section{Construction of the p403-GPD-hGR $\alpha$ expression vector}

There were no suited restriction sites for the cut-and-paste principle to get the full-length cDNA of the hGR $\alpha$ out of the pCDNA3/hGR $\alpha$ plasmid and paste it behind the strong GPD promoter of the p403-GPD-His vector. A full-length 
hGR $\alpha$ cDNA was therefore obtained by a PCR with proofreading polymerases. The 5 '-end primer contained a Xba 1 restriction site before the ATG start codon and had the following sequence: 5'-GCTCTAGAACTGATGGAC TCCAAAG-3'. The sequence of the $3^{\prime}$-end primer was: 5'-GCGGATCCAGTCACTTTTGATGAAA-3', containing a restriction site for BamH 1 just after the TGA stop codon. The 2,334-bp full-length hGR $\alpha$ PCR product was isolated from a $1 \%$ low-melt agarose gel and was ligated into the corresponding restriction sites of the p403-GPDHis vector. This $\mathrm{p} 403-\mathrm{GPD}-\mathrm{hGR} \alpha$-His vector was used to transform Epicurian Coli XL-2 Blue Cells. Digestion and PCR controls performed on isolated plasmids from single white colonies revealed several good clones (data not shown).

\section{Transformation of yeast cells}

Previously, a yeast $\mathrm{K} 20$ ( $\left.\mathrm{Ura}^{-}, \mathrm{His}^{-}, \mathrm{Leu}^{-}\right)$cell was transformed with a p406-HRE ${ }_{2}-\mathrm{CYC} 1$-yEGFP-Ura reporter construct and used to construct a yeast androgen bioassay [33]. The hormone-responsive element (HRE) used in that reporter plasmid is not only recognised by the hAR but can also bind an activated hGR $\alpha$ complex. That previously constructed $\mathrm{HRE}_{2}-\mathrm{CYC} 1$-yEGFP-Ura reporter yeast was used here to construct the yeast glucocorticoid bioassay by transforming it with the constructed p403-GPD-hGR $\alpha$-His vector. Transformation was performed with the lithium acetate procedure as described previously [29]. In short, the p403-GPD-hGR $\alpha$-His vector was linearised by cutting with Mcs I, which has a unique restriction site in the HIS3 marker gene (Histidine). Transformants were grown on minimal medium containing leucine only $(\mathrm{MM} / \mathrm{L})$. Stable transformants, i.e. with the receptor construct integrated in the yeast genome at the chromosomal location of the Histidine gene via homologous recombination, were checked with PCR controls on isolated chromosomal DNA. PCR I was performed with the primers that were also used to obtain the full-length cDNA of the human glucocorticoid receptor as described above and results in a 2,334-bp full-length hGR $\alpha$ PCR product. PCR II was performed with internal primers on the cDNA of the human glucocorticoid receptor. The 5'-end primer had the following sequence: 5'-CCCTGGTCGAACAGTTTTTT$3^{\prime}$. The sequence of the $3^{\prime}$-end primer was: $5^{\prime}$-AGCG TAGTCATGATCCTCCA-3'. This PCR control would generate a 539-bp PCR product. PCR III was performed with a 5 '-end primer on the GPD promoter and a 3 '-end primer on the CYC1 terminator. The sequence of the 5'and 3 '-end primers were 5'-CAGTTCCCTGAAATTAT TCCCCTAC-3' and 5'-GGGAGGGCGTGAATGTAAG3 ', respectively, and would result in a 2,590-bp PCR product.
The yeast glucocorticoid bioassay

Cultures of the yeast glucocorticoid biosensor were grown overnight at $30{ }^{\circ} \mathrm{C}$ with vigorous orbital shaking in the selective minimal medium supplemented with L-leucine $(\mathrm{MM} / \mathrm{L})$. At the late log phase, the culture was diluted in $\mathrm{MM} / \mathrm{L}$ to an optical density (OD) value at $630 \mathrm{~nm}$ was reached between 0.04 and 0.06 . For exposure, aliquots of $200 \mu \mathrm{l}$ of this diluted yeast culture were pipetted into each well of a 96-well plate and $2 \mu \mathrm{l}$ of a stock solution in DMSO was added to test the agonistic properties of the compounds. To test for anti-(gluco)corticoid properties, 1$\mu \mathrm{l}$ amounts of the stock solutions were co-exposed with either $1 \mu \mathrm{l}$ of budesonide or dexamethasone stock solutions known to cause either a half-maximal or a near-maximal response. DMSO and controls containing only budesonide or dexamethasone were included in each experiment; each sample concentration was assayed in triplicate. Exposure was performed for $24 \mathrm{~h}$ at $30{ }^{\circ} \mathrm{C}$ and orbital shaking $(125 \mathrm{rpm})$. Fluorescence and OD were measured at 0 and $24 \mathrm{~h}$ directly in a SynergyTM HT Multi-Detection Microplate Reader (BioTek Instruments Inc., USA) using excitation at $485 \mathrm{~nm}$ and emission at $530 \mathrm{~nm}$ for the fluorescent measurement. The fluorescent signal was corrected with the signals obtained with the supplemented MM containing DMSO solvent only, whilst the OD measurement at $630 \mathrm{~nm}$ was only performed to check whether a sample was toxic for the yeast cells.

The U2-OS human bone cell line-based GR-CALUX bioassay

The GR-CALUX cell line was obtained from BioDetection Systems B.V. (Amsterdam, the Netherlands). This GRCALUX bioassay is based on human osteoblastic osteosarcoma U2-OS cells (American Type Cell Culture) transfected with a hGR $\alpha$ expression plasmid and a luciferase reporter construct. The GR-CALUX bioassay is performed as described before $[30,34]$. In short, GR-CALUX cells were cultured in DF medium supplemented with $7.5 \%$ foetal calf serum (FCS) and $200 \mu \mathrm{g} / \mathrm{ml} \mathrm{G} 418$. For exposure, GR-CALUX cells were plated in 96-well plates with phenol red-free DF medium supplemented with 5\% dextran-coated charcoal-stripped FCS (DCC-FCS) at a volume of $200 \mu \mathrm{l}$ per well. Two days later, the medium was refreshed and cells were incubated with the compounds to be tested dissolved in DMSO; each compound concentration was analysed in triplicate (final DMSO concentration is $0.2 \%$ ). After $24 \mathrm{~h}$, the medium was removed, cells were lysed in Triton lysis buffer, and luciferase activity was measured using a Synergy HT Multi-Detection Microplate Reader (luminometer of BioTek Instruments Inc., USA). 


\section{Results}

For the development of specific bioassays, and especially in the case of bioassays for glucocorticoids, progestagens and androgens, the lack of endogenous receptors in yeast is a great advantage compared with mammalian cell lines as the consensus GRE is equal to the consensus progesterone and androgen-responsive element (PRE and ARE) and thus can also be activated by the PR and AR. This element is often referred to as the hormone-responsive element (HRE). To avoid potential cross talk in mammalian cell lines, lots of efforts were made to construct specific GREs, PREs and AREs [35]. However, up until now, such specific responsive elements do not seem to exist, and it is doubtful whether they will be found. So far, this resulted in cell lines that are not specific and suffer from cross talk [36, 37]. In order to fully exclude the cross talk, the latest AR, PR and GRCALUX tests are based on the human U2-OS bone cell line that, just as yeast cells, expresses no endogenous ER, AR, PR and GR [30, 34, 38]. Although less sensitive, yeast-based assays were shown to be more robust and specific compared with their mammalian analogues [5]. Here, a recombinant yeast cell was constructed that expresses the $\operatorname{hGR} \alpha$ and yEGFP as a reporter protein in response to glucocorticoids. Both the receptor construct as well as the reporter construct were stably integrated into the yeast genome by the use of yeast-integrating plasmids. High expression levels of the hGR $\alpha$ were obtained by placing the cDNA of the hGR $\alpha$ gene behind the strong constitutive yeast GPD promoter. Transfected strains were checked with PCR and the correct and specific functioning of this yeast glucocorticoid bioassay was studied by exposures to cortisol and other related compounds; the outcomes were critically compared with the specific U2-OS-based GR-CALUX bioassay.

Stable transfection of the HRE2-CYC1-yEGFP-Ura reporter yeast with the GPD-hGR $\alpha$-His receptor construct

The Saccharomyces cerevisiae strain K20 (Ura-, His-, Leu-) stably transformed with the p406-HRE2-CYC1-yEGFP-Ura reporter construct was described previously [33]. This strain was stably transformed with the p403-GPD-hGR $\alpha$-His receptor expression construct. Stable transformants, i.e. with the receptor construct integrated in the yeast genome at the chromosomal location of the Histidine gene via homologous recombination, were checked with PCR controls. Yeast chromosomal DNA of transformants was isolated and three PCR controls were performed. Figure 1 shows the gel electrophoresis results of these PCR controls. As expected, PCR I, II and III gave the specific 2,334-, 539- and 2,590-bp PCR products, demonstrating that the yeast glucocorticoid biosensor contains the p403-GPD-

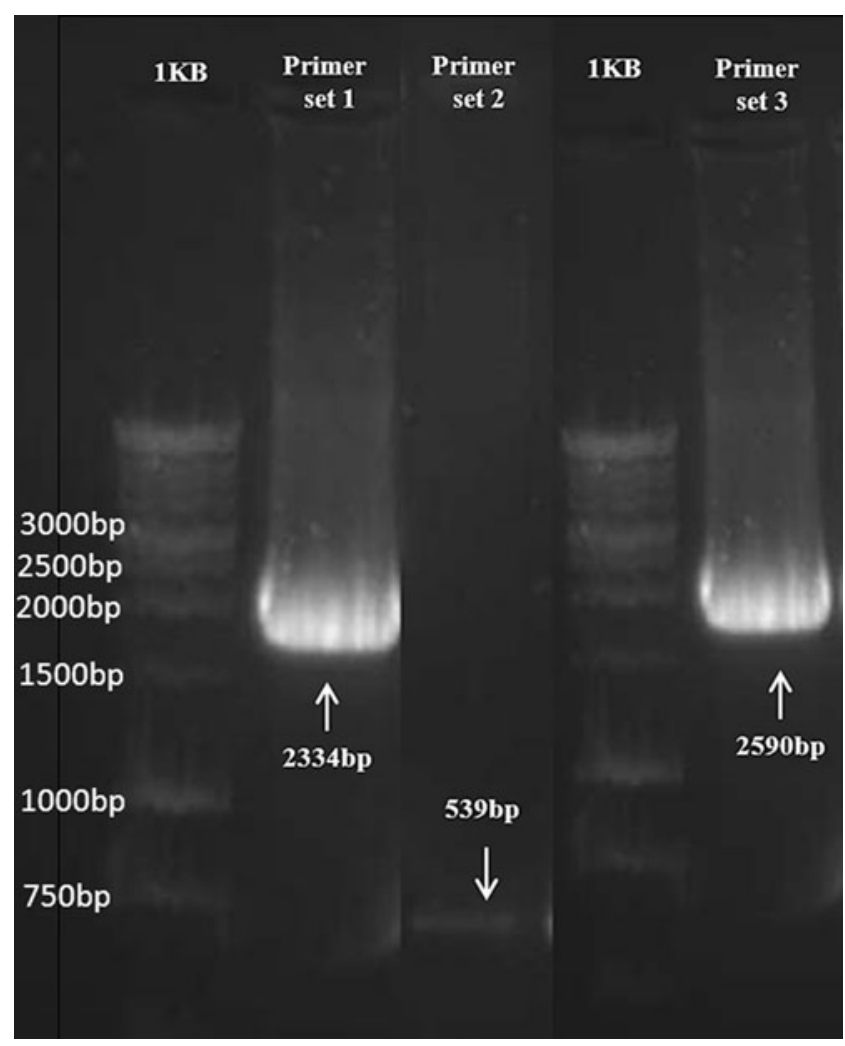

Fig. 1 PCR controls on yeast chromosomal DNA of p403-GPDhGR $\alpha$ receptor expression transformants. PCR I with primer set 1 gives a specific 2,334-bp product, PCR II with primer set 2 gives a specific 539-bp product, and PCR III with primer set 3 gives a specific 2,590-bp PCR product

$\mathrm{hGR} \alpha$ receptor expression vector stably integrated in the yeast genome.

Dose-response curves obtained with the yeast glucocorticoid bioassay

The dose-response curves for several natural and synthetic (gluco)corticoids are shown in Fig. 2. Aldoste-

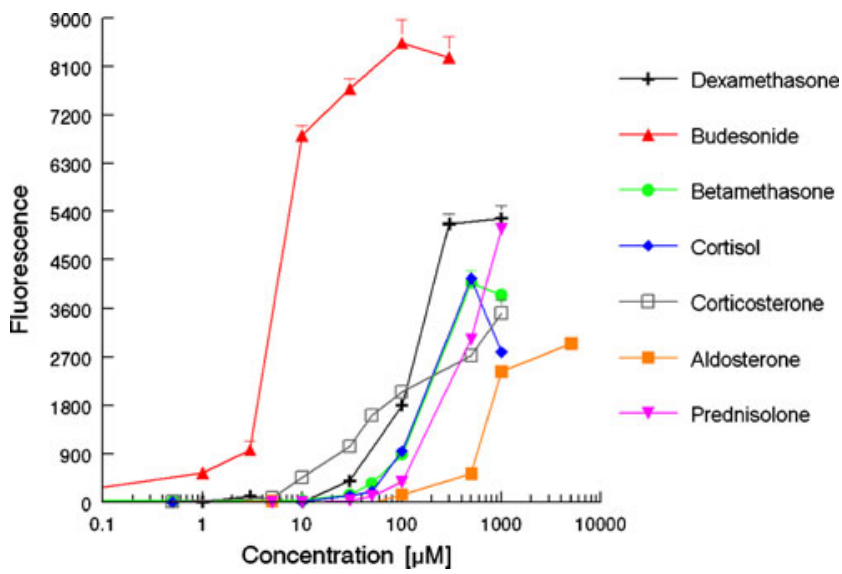

Fig. 2 Dose-response curves of several corticosteroids obtained in the yeast glucocorticoid bioassay 
rone, betamethasone, budesonide, corticosterone, cortisol, dexamethasone and prednisolone caused a dose-related increase in the production of yEGFP, demonstrating that these compounds are potent glucocorticoids. The bioassay showed a limit of detection, i.e. showing responses above the background signal plus three times the standard deviation on the mean background signal, of $0.5 \mu \mathrm{M}$ for the most potent glucocorticoid budesonide with a dynamic range from 0.5 to $10 \mu \mathrm{M}$ and in general low standard deviations $(<5 \%)$.

Steroids representative for other hormone receptors, like E2 for the ER and $5 \alpha$-DHT for the AR, showed no agonistic response, whilst $\mathrm{P} 4$, the natural ligand for the $\mathrm{PR}$, showed a small agonistic response. Table 1 shows the calculated $\mathrm{EC}_{50}$ values, i.e. the concentration giving a half-maximum response, and the relative corticoid potency (RCP), defined as the ratio between the $\mathrm{EC}_{50}$ of dexamethasone and the $\mathrm{EC}_{50}$ of the compound, for several compounds. The yeast glucocorticoid bioassay showed sensitivity towards all (gluco)corticoids tested, with the following range of potencies: budesonide $>>$ corticosterone $>$ dexamethasone $>$ cortisol $=$ betamethasone $>$ prednisolone $>$ aldosterone. Cortisone and prednisone showed no response in this bioassay.

Dose-response curves obtained with the U2-OS GR-CALUX bioassay

Figure 3 shows the dose-response curves for several natural and synthetic (gluco)corticoids as obtained in de U2-OS cell-based GR-CALUX bioassay. Aldosterone, betamethasone, corticosterone, cortisol, Dex and prednisolone caused a dose-related increase in luciferase activity, whilst cortisone and prednisone showed no response. These outcomes are similar as obtained with the yeast-based bioassay, although the ranking is slightly different. The most distinct differences are obtained for budesonide and fludrocortisone-21-acetate. Budesonide was much more potent than Dex in the yeast bioassay, but was equally potent in the GR-CALUX; fludrocortisone21 -acetate was inactive in yeast, but is active in the GRCALUX. There is a great difference in the limit of detection, which is at least three orders of magnitude lower for the active glucocorticoids in the U2-OS cellbased GR-CALUX. Table 1 shows the calculated $\mathrm{EC}_{50}$ and the RCP for several compounds as obtained in the GR-CALUX.

\section{Anti-glucocorticoid activity}

The yeast glucocorticoid bioassay was further examined by testing compounds that are known to display antiglucocorticoid activity. Figure 4 shows the agonistic and antagonistic activities of the known partial GR agonist mifepristone (RU486, which is mostly referred to as a PR and GR antagonist) and three additional synthetic compounds that were classified as GR antagonists by their manufacturer due to their response in a mammalian cellbased in vitro receptor-reporter gene assay. The antagonistic properties were examined by co-exposure with a concentration of dexamethasone that induced a half-maximal or sub-maximal response, 150 or $500 \mu \mathrm{M}$, respectively.
Table 1 Calculated $\mathrm{EC}_{50}$ value and RCP for several natural and synthetic steroids as determined in the yeast glucocorticoid and U2-OS GR-CALUX bioassays

\footnotetext{
${ }^{\mathrm{a}}$ Triamcinolone and progesterone are slightly active in the yeast bioassay, but their maximal responses are only about $10 \%$ and $6 \%$, respectively, of the maximal response as obtained with dexamethasone; thus, it is not appropriate to give an $\mathrm{EC}_{50}$ value or RCP. Progesterone is also active in the GR-CALUX, but its response is only about $4 \%$ of the maximal response as obtained with dexamethasone

${ }^{\mathrm{b}}$ Mifepristone is not active as an agonist in the GR-CALUX and acts as a pure antagonist in this assay
}

\begin{tabular}{llcccc}
\hline \multirow{2}{*}{ Compound } & \multicolumn{2}{l}{ Yeast glucocorticoid assay } & & \multicolumn{2}{l}{ GR-CALUX } \\
\cline { 2 - 3 } \cline { 5 - 6 } & $\mathrm{EC}_{50}(\mu \mathrm{M})$ & $\mathrm{RCP}$ & & $\mathrm{EC}_{50}(\mathrm{nM})$ & $\mathrm{RCP}$ \\
\hline Dexamethasone & 120 & 1.0 & & 2.2 & 1.0 \\
Budesonide & 6 & 20 & 2.2 & 1.0 \\
Betamethasone & 149 & 0.8 & & 11 & 0.2 \\
Cortisol & 123 & 1.0 & & 37 & 0.06 \\
Corticosterone & 71 & 1.7 & & 80 & 0.03 \\
Cortisone & Not active & 0.0 & & Not active & 0 \\
Aldosterone & 705 & 0.2 & & 495 & 0.004 \\
Fludrocortisone-21-acetate & Not active & 0.0 & & 11 & 0.2 \\
Prednisolone & 643 & 0.2 & & 12 & 0.2 \\
Prednisone & Not active & 0.0 & & Not active & 0 \\
Triamcinolone & Active & Active & & 19 & 0.1 \\
Mifepristone & 578 & 0.2 & Not active & 0 \\
17ß-Estradiol (E2) & Not active & 0.0 & Not active & 0 \\
$5 \alpha$-Dihydrotestosterone & Not active & 0.0 & Not active & 0 \\
Progesterone (P4) & Active & Active & Active & active \\
\hline
\end{tabular}




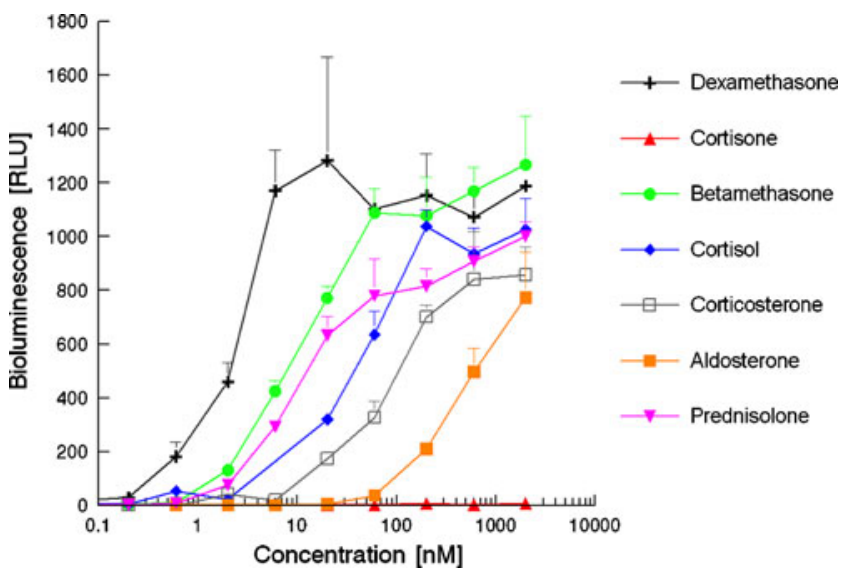

Fig. 3 Dose-response curves of several corticosteroids obtained in the U2-OS cell-based GR-CALUX bioassay

Figure 4 shows that all compounds were active in yeast and acted as agonists in the absence of dexamethasone. Figure 4 also shows that Org 34116 was not able to inhibit the response caused by dexamethasone, and Org 34850 and Mifepristone only slightly acted as GR antagonists at concentrations between 10 and $100 \mu \mathrm{M}$ and 50 and $500 \mu \mathrm{M}$, respectively. Org 34517 clearly acted as a GR antagonist when co-exposed with a concentration of dexamethasone that caused a nearmaximal response, i.e. $500 \mu \mathrm{M}$ dexamethasone.

Figure 5 shows the glucocorticoid and anti-glucocorticoid activities of mifepristone and Org 34517 as obtained in the U2-OS-based GR-CALUX bioassay. The antagonistic properties were examined by co-exposure with a concentration of dexamethasone that induced a half-maximal or sub-maximal response, 1 or $10 \mathrm{nM}$, respectively. Both compounds acted as pure GR antagonists in this bioassay. Also, Org 34116 and 34850 acted as pure GR antagonist in the U2-OS GR-CALUX, and there was no difference in potency compared with Org 34517 (fully identical dose-response curves for all three Org compounds; data for the other two Org compounds are therefore not shown). a

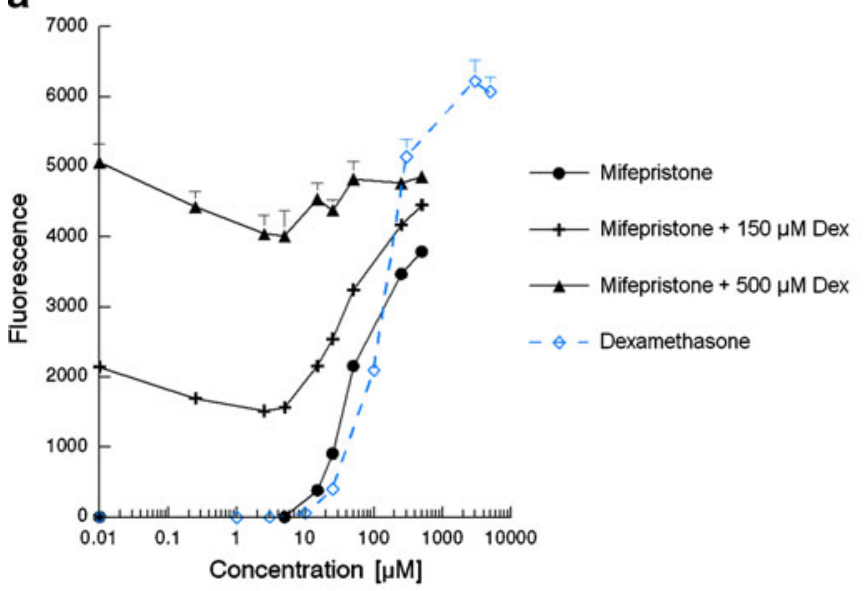

C

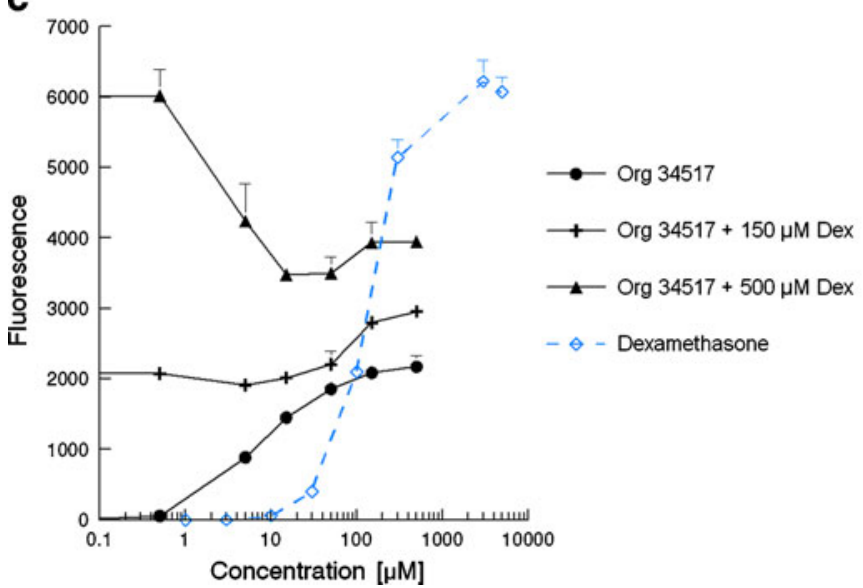

b

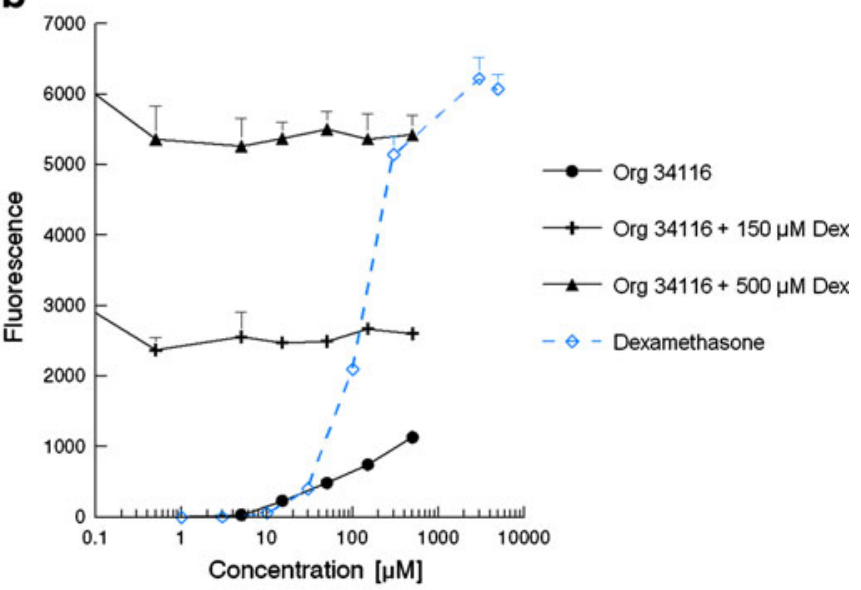

d

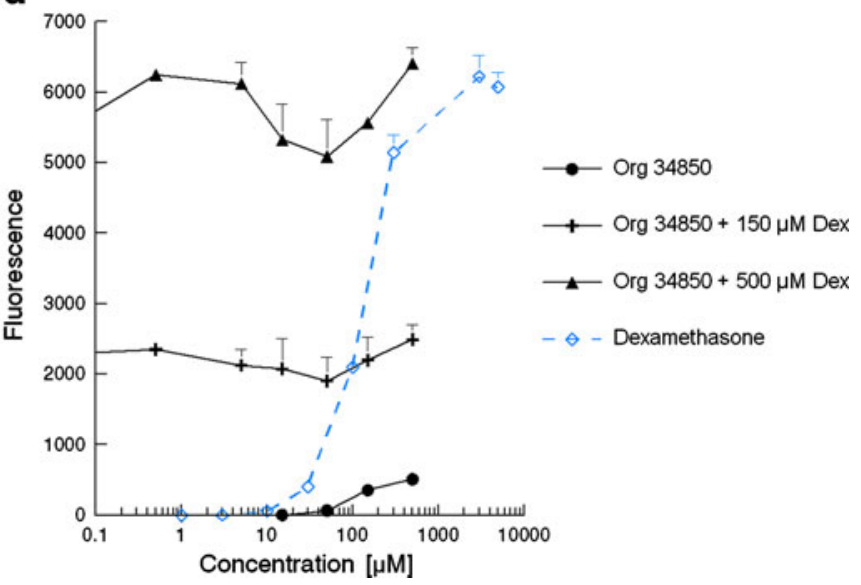

Fig. 4 GR agonistic and antagonistic characteristics of mifepristone (a), Org 34116 (b), Org 34517 (c) and Org 34850 (d) determined in the yeast GR bioassay 
a

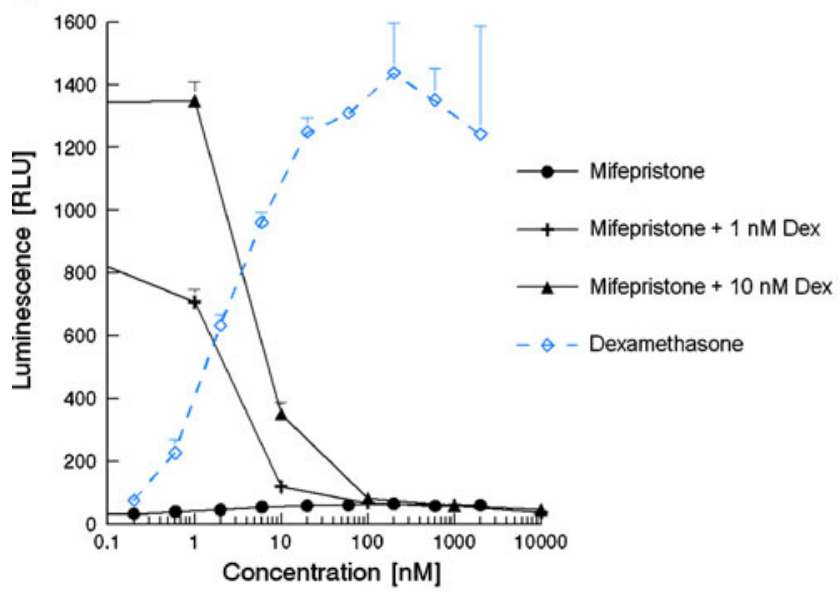

Fig. 5 GR agonistic and antagonistic characteristics of mifepristone bioassay

Glucocorticoid and anti-glucocorticoid activity of environmental pollutants

Figure 6 shows the agonistic and antagonistic responses of several PCBs as obtained in the yeast glucocorticoid bioassay. The antagonistic properties were examined by co-exposure with a concentration of budesonide that induced a half-maximal or sub-maximal response, 5 or $5 \mu \mathrm{M}$, respectively. It shows that PCB47 and PCB100 only act as GR antagonists, and this antagonistic response can only be envisaged when these compounds are co-exposed with $5 \mu \mathrm{M}$ budesonide. PCB92 acts as a GR antagonist when co-exposed with either 5 or $50 \mu \mathrm{M}$ budesonide, but also has a slight agonistic effect on itself. PCB101 is the most potent PCB tested; it displays an agonistic effect that is almost comparable with that of triamcinolone and progesterone and is also the strongest

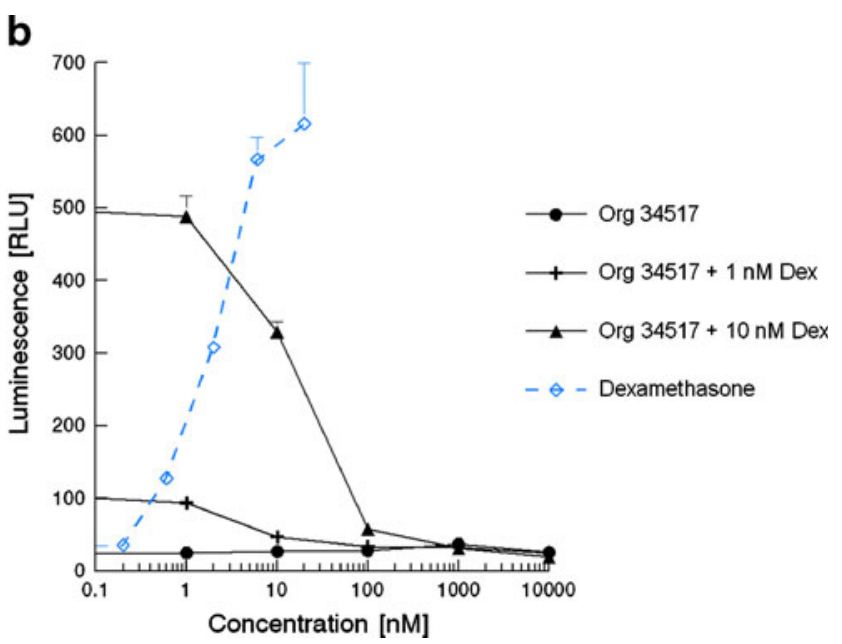

a

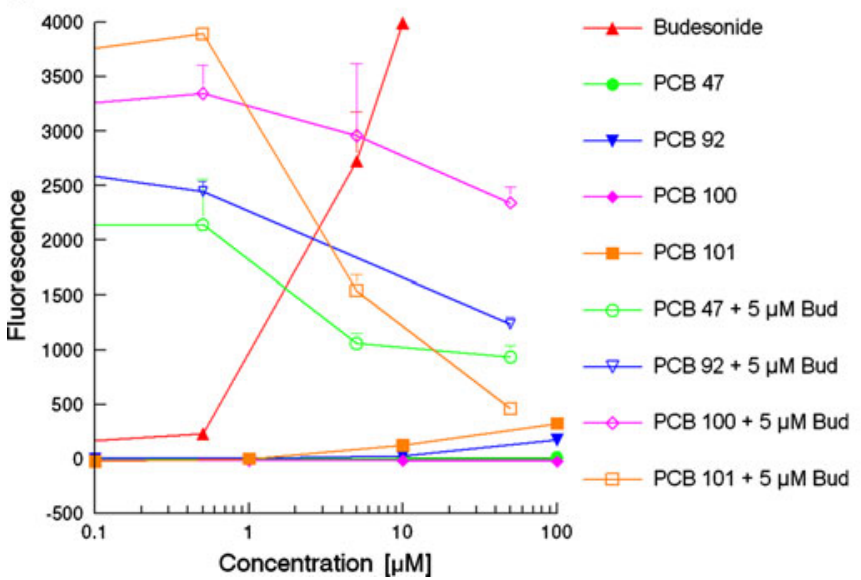

GR antagonist, capable of inhibiting 50\% of the response caused by $50 \mu \mathrm{M}$ budesonide and almost fully inhibiting the response caused by $5 \mu \mathrm{M}$ budesonide.

\section{Discussion}

In humans, the $\mathrm{hGR} \alpha$, in the absence of glucocorticoids, is present in the cytoplasm and is bound to a complex of proteins. This chaperone complex stabilizes the unliganded $\mathrm{hGR} \alpha$ in such a way that the LBD is able to bind glucocorticoids. Heat shock protein 90 (HSP90) is one of the most studied members of this chaperone complex $[39,40]$. The HSP90 chaperone protein is expressed in most, if not all, cells and has an important role in the protein folding process. This protein folding mechanism is a highly conserved mechanism, and many organisms

\section{b}

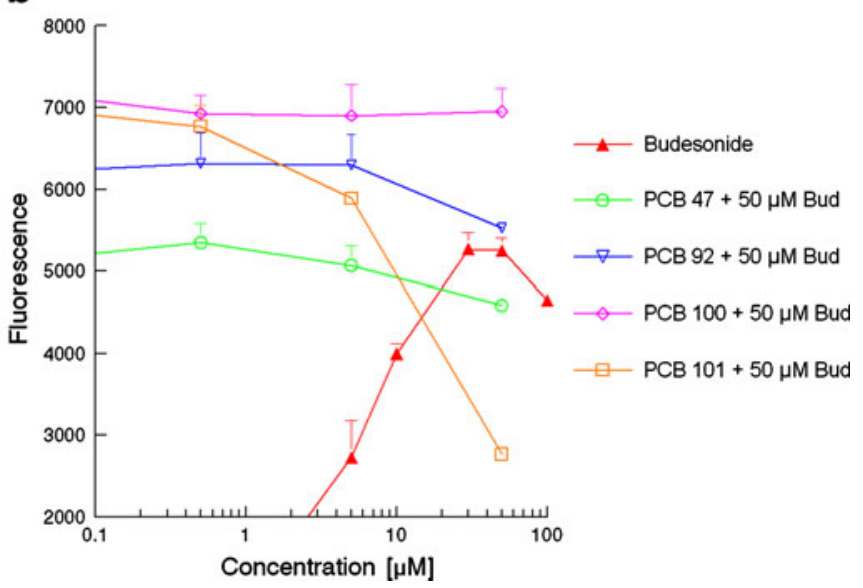

Fig. 6 GR agonistic and antagonistic characteristics of several PCBs determined in the yeast GR bioassay: a Alone and in combination with $5 \mu \mathrm{M}$ budesonide; b In combination with $50 \mu \mathrm{M}$ budesonide 
possess their own HSP90 homologs. For instance, in yeast, like $S$. cerevisiae, there are no steroid hormone receptors present, but genetic analyses revealed two HSP genes encoding the similar isoforms HSP82 and HSC82 [41]. As the transcription activation machinery in yeast is highly conserved, the construction of yeast-based bioassays for hormonal activities only requires the introduction of a receptor construct and a reporter construct. Indeed, it has been demonstrated that steroid hormone receptors, such as $\mathrm{hER} \alpha, \mathrm{hER} \beta, \mathrm{hAR}$ and $\mathrm{hPR}_{\mathrm{B}}$, exogenously expressed in $S$. cerevisiae, can reach a hormone-binding conformation and, in the presence of the proper ligand, activate a hormoneinducible reporter gene. This study shows that also the hGR $\alpha$ can reach an active state in yeast upon binding of a ligand and is subsequently able to activate the transcription machinery on the DNA from a hormone-responsive element.

The new yeast glucocorticoid bioassay is less sensitive than its mammalian analogue, e.g. $\mathrm{EC}_{50}$ for budesonide of about $5 \mu \mathrm{M}$ in yeast and $2 \mathrm{nM}$ in the GR-CALUX. A lower sensitivity was expected as also the yeast-based assays for the detection of oestrogens, androgens and progestagins have been shown to be less sensitive than their mammalian analogues [29, 30, 33, 42-44]. However, the sensitivity of this yeast glucocorticoid assay is relatively very low. This becomes clear when the $\mathrm{EC}_{50}$ values for $\mathrm{E} 2, \mathrm{P} 4, \mathrm{~T}$ and Dex of respectively $0.5,1,50$ and $100.000 \mathrm{nM}$ in yeast-based ER, PR, AR and GR bioassays are compared with their U2OS-based CALUX analogues, with $\mathrm{EC}_{50}$ values of respectively $0.02,0.6,0.7$ and $0.7 \mathrm{nM}[29,30,33,42-44]$. The relatively very low sensitivity of the yeast glucocorticoid bioassay is most probably due to the absence of the human HSP90 chaperone protein; the present data thus suggest that HSP90 is more needed in yeast to obtain optimal hGR $\alpha$ activity than it is needed to obtain fully active ER, PR and AR.

On the other hand, the yeast GR bioassay is specific and the outcomes with different compounds correlate well with their known characteristics. Cortisol and corticosterone are known active endogenous glucocorticoids, aldosterone is an endogenous corticoid that is less active on the GR and more active on the MR, and budesonide, dexamethasone, betamethasone and prednisolone are known active synthetic glucocorticoids. Budesonide, dexamethasone and prednisolone are known to be relatively potent, whilst betamethasone is known to be moderately potent. Although budesonide is relatively very potent in the yeast glucocorticoid bioassay, the potency ranking of these active compounds is as expected. Moreover, the inactivity of cortisone, prednisone and fludrocortisone-21-acetate in the yeast glucocorticoid bioassay is also as expected. Corticosterone is an active intermediate in the synthesis of both cortisol and aldosterone, but cortisone is the inactive metabolite of cortisol that is formed by $11 \beta$-steroid dehydrogenase in peripheral tissues. Prednisone is a synthetic prodrug that is converted by the liver into the active drug prednisolone, and fludrocortisone-21acetate is a synthetic drug that is mainly known as a mineralocorticoid receptor agonist. Regarding the specificity, both assays showed a small response when cells were exposed to progesterone. This small GR-mediated corticoid activity of progesterone is as expected as progesterone was already classified as a partial glucocorticoid agonist before [45]. However, the activity of fludrocortisone-21-acetate in the U2OS-based GR-CALUX was unexpected as cortisone was inactive in this mammalian cell assay. Possibly, the human bone cell is specifically able to convert fludrocortisone-21acetate into a cortisol analogue and displays esterase activity, or perhaps the U2-OS cells express the MR and thus suffer from cross talk [38].

Regarding the antagonistic characteristics of the compounds tested, only Org 34517 was able to demonstrate clear GR antagonistic properties in yeast and mifepristone; the three Org compounds mainly acted as GR agonists in the yeast bioassay, whilst all four compounds acted as pure GR antagonists in the U2-OS GR-CALUX. However, mifepristone is a partial PR and GR agonist. For its PR antagonist properties, mifepristone was mainly used as an arbotifacient in the first 2 months of pregnancy, but mifepristone is also known to suppress the GR levels in the human decidua and placenta; the latter might be part of the mechanism of mifepristone in causing abortion too [46]. Thus, the anti-glucocorticoid in vivo effect of mifepristone is at least partly caused by suppressing the GR levels instead of directly acting as a GR antagonist. Moreover, the outcome as observed in the yeast assay, i.e. mifepristone acting as a GR agonist, correlates well with the observation of Zhang et al. [47] showing that mifepristone acts as a GR agonist in monkey COS-7 and mouse E8.2.A3 cells with high GR levels, most probably similar as in yeast, where the GR is strongly and continuously expressed. In addition, mifepristone was also classified as an AR agonist and AR antagonist [48]. Thus, this compound displays several activities on several nuclear receptors and its response is cell type-specific; the latter might be related to GR levels.

In general, mammalian cell-based assays for nuclear receptors are more sensitive than yeast-based assays, but mammalian cells need serum to grow, and as serum contains small amounts of steroids and other growth factors, the exposure of these cells to compounds and sample extracts has to be performed in media with stripped serum. Moreover, the measurement of the fluorescence (yEGFP) can be followed as a function of incubation time and is easier, quicker and cheaper than the measurement of the $\beta$-galactosidase or luciferase activity, which requires cell wall disruption and/or the addition of expensive substrates. In addition, it has been demonstrated that $S$. 
cerevisiae contains none of the enzymes activities in the steroidogenesis, e.g. aromatase, $5 \alpha$-reductase, $3 \beta$-HSD or $17 \beta$-HSD, which makes yeast-based assays very specific as differences in metabolism in human cell lines have led to different outcomes [5]. However, despite the differences, different assay types are complementary and needed together to be able to elicit the mechanism of actions of compounds and their metabolites [5].

In summary, although the new yeast glucocorticoid bioassay is relatively insensitive and might be less suited for sample analysis requiring a low sensitivity, it is specific. Just as the U2-OS GR-CALUX, it is able to detect the known agonistic properties of natural and synthetic (gluco) corticoids, whilst steroids representative for other hormone receptors showed no response. The GR yeast bioassay is thus suited to test the characteristics of pure compounds; this was further demonstrated with several environmental PCB pollutants that are known to possess endocrinedisrupting potencies as these PCBs also effected the activation of the GR in the yeast bioassay, including GR antagonism. PCB101, together with its $3 \mathrm{MeSO}_{2}$ metabolite, one of the most abundant PCBs present in humans and wildlife, turned out to be rather potent. It displayed an agonistic effect that was almost comparable with that of the partial GR agonist progesterone. PCB101 was also a strong GR antagonist, almost capable of fully inhibiting the response caused by $5 \mu \mathrm{M}$ budesonide. The physiologic relevance of the latter should be explored further.

Acknowledgements This work was supported by the Dutch Ministry of Economic Affairs, Agriculture and Innovation (project no. WOT-02-003-038).

Open Access This article is distributed under the terms of the Creative Commons Attribution Noncommercial License which permits any noncommercial use, distribution, and reproduction in any medium, provided the original author(s) and source are credited.

\section{References}

1. Pike MC, Spicer DV, Dahmoush L, Press MF (1993) Estrogens, progesterons, normal breast cell proliferation, and breast cancer risk. Epidemiologic Reviews 15:17-35

2. Skakkebæk NE, Jørgensen N, Main KM, Rajpert-DeMeyts E, Leffers H, Andersson A, Juul A, Carlsen E, Mortensen GK, Jensen TK, Toppari J (2006) Is human fecundity declining? Int J Androl 29:2-11

3. Jenkins RL, Wilson EM, Angus RA, Howell WM, Kirk M (2003) Androstenedione and progesterone in the sediment of a river receiving paper mill effluent. Toxicol Sci 73:53-59

4. Balabanic D, Rupnik M, Klemencic AK (2011) Negative impact of endocrine-disrupting compounds on human reproductive health. Reprod Fertil Dev 23:403-416

5. Bovee TFH, Pikkemaat MG (2009) Bioactivity-based screening of antibiotics and hormones. J Chromatography A 1216:80358050
6. Akner G, Wikstrom AC, Mossberg K, Sundqvist KG, Gustafsson JA (1994) Morphometric studies of the localization of the glucocorticoid receptor in mammalian cells and of glucocorticoid hormone-induced effects. J Histochem Cytochem 42:645-657

7. Francke U, Foellmer BE (1989) The glucocorticoid receptor gene. Genomics 4:610-612

8. Laudet V, Auwerx J, Gustafsson JA, Wahli W (1999) A unified nomenclature system for the nuclear receptor superfamily. Cell 97:1611-163

9. Lu NZ, Cidlowski JA (2004) The origin and functions of multiple human glucocorticoid receptor isoforms. Ann N Y Acad Sci 1024:102-123

10. De Rijk RH, Schaaf M, De Kloet ER (2002) Glucocorticoid receptor variants: clinical implications. J Steroid Biochemistry Molecular Biology 81:103-122

11. Buckingham J (2006) Glucocorticoids: exemplars of multitasking. Br J Pharmacol 147:258-268

12. Kapoor A, Petropoulos S, Matthews SG (2008) Fetal programming of hypothalamic-pituitary-adrenal (HPA) axis function and behaviour by synthetic glucocorticoids. Brain Res Reviews 57:586-595

13. Bamberger CM, Bamberger AM, De Castro M, Chrousos GP (1995) Glucocorticoid receptor $\beta$, a potential endogenous inhibitor of glucocorticoid action in humans. J Clin Investig 95:2435-2441

14. Hecht K, Carlstedt-Duke J, Stierna P, Gustafsson JA, Brönnegård M, Wikström AC (1997) Evidence that the $\beta$-isoform of the human glucocorticoid receptor does not act as a physiologically significant repressor. J Biol Chem 272:26659-26664

15. Oakley RH, Jewell CM, Yudt MR, Bofetiado DM, Cidlowski JA (1999) The dominant negative activity of the human glucocorticoid receptor $\beta$-isoform. J Biol Chem 274:27857-27866

16. Labrie F, Belanger A, Cusan L, Candas B (1997) Physiological changes in dehydroepiandrosterone are not reflected by serum levels of active androgens and estrogens but of their metabolites: intracrinology. J Clinical Endocrinal Metabolism 82:2403-2409

17. Conley AJ, Bird IM (1997) The role of cytochrome P450 17 $\alpha$ hydroxylase and $3 \beta$-hydroxysteroid dehydrogenase in the integration of gonadal and adrenal steroidogenesis via the $\Delta 5$ and $\Delta 4$ pathways of steroidogenesis in mammals. Biol Reprod 56:789-799

18. Bird IM, Hanley NA, Word RA, Mathis JM, McCarthy JL, Mason JI, Rainey WE (1993) Human NCI-H295 adrenocortical carcinoma cells: a model for agiotensin II-responsive aldosterone secretion. Endocrinology 133:1555-1561

19. Hasan EA, Jessop DS, Power LL, Mink PT, Kirwan JR (2009) Use of the dexamethasone-corticotrophin releasing hormone test to assess hypothalamic-pituitary-adrenal axis function in rheumatoid arthritis. Int J Endocrinol, vol 2009, Article ID 391284, 6 pp. doi: $10.1155 / 2009 / 391284$

20. Kim SJ, Kim K, Kim BS, Kim CY, Suh C, Huh J, Lee SW, Kim JS, Cho J, Lee GW, Kang KM, Eom HS, Pyo HR, Ahn YC, Ko YH, Kim WS (2009) Phase II trial of concurrent radiation and weekly cisplatin followed by VIPD chemotherapy in newly diagnosed, stage IE to IIE, nasal, extranodal NK/T-cell lymphoma: consortium for improving survival of lymphoma study. J Clin Oncol 27:6027-6032

21. Umberger EJ (1975) Products marketed to promote growth in food-producing animals: steroid and hormone products. Toxicology $3: 3-21$

22. Courtheyn D, Le Bizec B, Brambilla G, De Brabander HF, Cobbaert E, Van de Wiele M, Vercammen J, De Wasch K (2002) Recent developments in the use and abuse of growth promoters. Analytrica Chimica Acta 473:71-82

23. Huetos O, Jimenez M, Ajenjo E, San Andres M, Reuvers TBA (2003) Determination of dexamethasone in urine by gas chromatography 
with negative chemical ionization mass spectrometry. J Chromatography $B$ 788:137-146

24. Odore R, Badino P, Barbero R, Cuniberti B, Pagliasso S, Girardi C, Re G (2007) Regulation of tissue $\beta$-adrenergic, glucocorticoid and androgen receptors induced by repeated exposure to growth promoters in male veal calves. Res Vet Sci 83:227-233

25. Mansell PD, Cameron AR, Taylor DP, Malmo J (2006) Induction of parturition in dairy cattle and its effects on health and subsequent lactation and reproductive performance. Aust Vet $\mathrm{J}$ $84: 312-316$

26. EC Council Directive No. $96 / 22$

27. EU Regulation No. 37/2010. Official Journal of the European Union L 15/1-L15/72

28. Letcher RJ, Lemmen JG, Van der Burg B, Brouwer A, Bergman A, Giesy JP, Van den Berg M (2002) In vitro antiestrogenic effects of aryl methyl sulfone metabolites of polychlorinated biphenyls and 2,2-bis(4-chlorophenyl)-1,1-dichloroethene on 17betaestradiol-induced gene expression in several bioassay systems. Toxicol Sci 69:362-372

29. Bovee TFH, Helsdingen JR, Koks PD, Kuiper HA, Hoogenboom LAP, Keijer J (2004) Development of a rapid yeast estrogen bioassay, based on the expression of green fluorescent protein. Gene 325:187-200

30. Van der Linden SC, Heringa MB, Man HY, Sonneveld E, Puijker LM, Brouwer A, Van der Burg B (2008) Detection of multiple hormonal activities in wastewater effluents and surface water, using a panel of steroid receptor CALUX bioassays. Environ Sci Technol 42:5814-5820

31. Mumberg D, Müller R, Funk M (1995) Yeast vectors for the controlled expression of heterologous proteins in different genetic backgrounds. Gene 156:119-122

32. Bovee TFH, Helsdingen JR, Rietjens IMCM, Keijer J, Hoogenboom LAP (2004) Rapid yeast estrogen bioassays stably expressing human estrogen receptors $\alpha$ and $\beta$, and green fluorescent protein: a comparison of different compounds with both receptor types. J Steroid Biochemistry Molecular Biology 91:99-109

33. Bovee TFH, Helsdingen JR, Hamers ARM, Van Duursen MBM, Nielen MWF, Hoogenboom LAP (2007) A new highly specific and robust yeast androgen biosassay for the detection of agonist and antagonists. Anal Bioanal Chem 389:1549-1558

34. Sonneveld E, Riteco JAC, Jansen HJ, Pieterse B, Brouwer A, Schoonen WG, Van der Burg B (2006) Comparison of in vitro and in vivo screening models for androgenic and estrogenic activities. Toxicol Sci 89:173-187

35. Brodie J, McEwan IJ (2005) Intra-domain communication between the N-terminal and DNA-binding domains of the androgen receptor: modulation of androgen response element DNA binding. J Mol Endocrinol 34:603-615
36. Blankvoort BMG, De Groene EM, Van Meeteren-Kreikamp AP, Witkamp RF, Rodenburg RJT, Aarts JMMJG (2001) Development of an androgen reporter gene assay (AR-LUX) utilising a human cell line with an endogenously regulated androgen receptor. Anal Biochem 298:93-102

37. Willemsen P, Scippo M, Maghuin-Rogister G, Martial JA, Muller $M$ (2005) Enhancement of steroid receptor-mediated transcription for the development of highly responsive bioassays. Anal Bioanal Chem 382:894-905

38. Sonneveld E, Pieterse B, Schoonen WG, Van der Burg B (2011) Validation of in vitro screening models for progestagenic activities: inter-assay comparison and correlation with in vivo activity in rabbits. Toxicology In Vitro 25:545-554

39. Dennis M (1988) Two step purification and N-terminal amino acid sequence analysis of the rat $\mathrm{Mr} 90000$ heat shock protein. Anal Biochem 173:405-411

40. Johnson JL, Toft DO (1995) Binding of p23 and hsp90 during assembly with the progesterone receptor. Mol Endocrinol 9:670-678

41. Chang HJ, Lindquist S (1994) Conservation of Hsp90 macromolecular complexes in Saccharomyces cerevisiae. J Biol Chem 269:24983-24988

42. Routlegde EJ, Sumpter JP (1997) Structural features of alkylphenolic chemicals associated with estrogenic activity. J Biol Chem 272:3280-3288

43. Gaido KW, Leonard LS, Lovell S, Gould JC, Babaï D, Portier CJ, McDonnell DP (1997) Evaluation of chemicals with endocrine modulating activity in a yeast-based steroid hormone receptor gene transcription activation assay. Toxicol Appl Pharmacol 143:205-212

44. Chatterjee S, Kumar V, Majumder CB, Roy P (2008) Screening of some anti-progestin endocrine disruptors using a recombinant yeast based in vitro bioassay. Toxicology In Vitro 22:788-798

45. Hackney JF, Holbrook NJ, Grasso RJ (1981) Progesterone as a partial glucocorticoid agonist in L929 mouse fibroblasts: effect on cell growth, glutamine synthetase induction and glucocorticoid receptors. J Steroid Biochemistry 14:971-977

46. Chan CCW, Lao TT, Ho PC, Sung EOP, Cheung ANY (2003) The effect of mifepristone on the expression of steroid receptors in human decidua and placenta: a randomized placebo-controlled double-blind study. Clinical Endocrinology Metabolism 88:5846-5850

47. Zhang S, Jonklaas J, Danielsen M (2007) The glucocorticoid agonist activities of mifepristone (RU486) and progesterone are dependent on glucocorticoid receptor levels but not on $\mathrm{EC}_{50}$ values. Steroids 72:600-608

48. NIH Publication No. 03-4503 